\title{
Health-Related Consequences of Physical and Sexual Violence: Women in the Military
}

\author{
ANNE G. SADLER, RN, PhD, BRENDA M. BOOTH, PhD, DEANNA NIELSON, PhD, \\ AND BRADLEY N. DOEBBELING, MD, MSc
}

Objectives: To identify differences in health-related quality of life among women veterans who were raped, physically assaulted (not in the context of rape or domestic violence), both, or neither during military service.

Methods: We did a cross-sectional telephone survey of a national sample of 558 women veterans who served in Vietnam and subsequent eras of military service. A stratified survey design selected subjects according to era of service and location. The interview included socioeconomic information, lifetime violence history, the Women's Military Environment Survey to assess women's military experiences, and the Medical Outcomes Study Short Form-36 to assess health-related quality of life.

Results: Five hundred thirty-seven women completed the interview. Half (48\%) experienced violence during military service, including rape $(30 \%)$, physical assault $(35 \%)$, or both $(16 \%)$. Women who were raped or dually victimized were more likely to report chronic health problems, prescription medication use for emotional problems, failure to complete college, and annual incomes less than \$25,000 $(P<.05)$. Women who were physically assaulted or raped reported significantly lower health-related quality of life $(P<.05)$. Those who had both traumas reported the most severe impairment, comparable to women with chronic illnesses.

Conclusion: This study suggests that the sequelae of violence against women are an important public health concern. More than a decade after rape or physical assault during military service, women reported severely decreased health-related quality of life, with limitations of physical and emotional health, educational and financial attainment, and severe, recurrent problems with work and social activities. (Obstet Gynecol 2000;96:473-80.)

From The Iowa City Veterans' Affairs Medical Center, Iowa City, Iowa; The HSRED Field Program for Mental Health Research, Department of Psychiatry, The University of Arkansas for Medical Sciences, Little Rock, Arkansas; and the Department of Internal Medicine, The College of Medicine, and the Department of Epidemiology, The College of Public Health, The University of Iowa, Iowa City, Iowa.

Supported by The Department of the Army (Grant No. DAMD1795-5073).
Violence against American women is surprisingly frequent. Estimates are that one in five women are raped by 21 years of age. ${ }^{1}$ Although the incidence of first rape peaks in young women 12 to 17 years old, ${ }^{2}$ more than 60,000 rapes of women over age 50 are reported annually. ${ }^{3}$ Violence has been identified as a widespread occupational risk for women. Nonfatal assaults account for $42 \%$ of women's workplace injuries. ${ }^{4}$ More women die from workplace violence than from job-related accidents. ${ }^{5}$ Furthermore, the risk of workplace violence appears heightened in some occupations, such as military service. ${ }^{6,7}$

Violence recently has gained attention as a women's health issue that has been neglected. ${ }^{8}$ Clinical research has focused on the psychologic effects of sexual victimization with limited recognition of the health-related consequences. However, a growing body of literature indicates that sexual violence can have life-long medical repercussions. ${ }^{9}$ World Bank economists estimated that sexual victimization accounts for almost 1 in every 5 health-years of life lost among young women (age $15-44$ years). ${ }^{10}$

One half of rape victims sustain vaginal or perineal trauma. ${ }^{11}$ Fifteen percent of victims have significant vaginal tears and $1 \%$ require surgical repair of lacerations. ${ }^{11}$ Thirty-nine percent of rape victims sustain nongenital injuries, over half of which require medical attention. ${ }^{11,12}$ Sexually transmitted diseases (STDs) occur in up to $43 \%$ of victims. ${ }^{13}$ Rape is associated with increased symptoms involving nearly all body systems, higher levels of injurious health behaviors, and greater medical service use. ${ }^{9,14}$ Chronic pain, such as pelvic pain, headache, fibromyalgia, and gastrointestinal disorders, frequently occurs in women who have been raped. ${ }^{9,14,15}$

Data suggest that there are predictable and distinguishable medical and psychologic sequelae of violence toward women and that adverse effects continue throughout life. However, the degree to which chronic 
illness is an effect of violence is not known. Healthrelated quality of life is defined as self-assessed functional ability and well-being, independent of age, disease, or treatment. It is important to understand the health-related quality of life of women who have been raped or physically assaulted to determine what might lead to chronic conditions after victimization. That knowledge could improve clinical practice and costeffectiveness of health care. Prior research has often not distinguished between physical and sexual violence, so it is not known whether there are unique health-related effects of workplace rape versus physical assault. Thus, the major objective of this study was to compare differences in health-related quality of life between women veterans who, while in the military, were raped, physically assaulted (not in the context of rape or domestic violence), raped and physically assaulted, or neither.

\section{Methods}

In a pilot study, sexual violence was reported more often by women who served in Vietnam and subsequent eras, compared with those who served before then $(29 \%$ versus $3 \% ; n=333)$. Therefore, a historical cohort of women veterans who served in the Vietnam, post-Vietnam, or Persian Gulf War era was selected from the Department of Veterans' Affairs comprehensive women's health care centers' registries $(n=8693)$. Women veterans in those registries had either obtained treatment at a Veterans Affairs Medical or Vet Center, sought service-connected disability, attended veterans conferences, or answered advertisements requesting registration for mailing lists. We selected regions of the United States, including the northeast (Boston), south (Durham and Tampa), mid-central (Minneapolis and Chicago); and west coast (Los Angeles). From that cohort, random samples were selected $(n=2172)$ by region and era of service. Randomization was done using a computer-generated random numbers table.

Information summaries and consent forms were sent with postage-paid preaddressed return envelopes. Mailings were distributed over 6 months (September 1996 to March 1997) to minimize lag between consent and participation. Follow-up letters were mailed to nonresponders approximately 6 weeks after initial contact.

Subjects who returned consent forms were scheduled for computer-assisted telephone interviews by the University of Iowa Social Science Institute (Iowa City, IA). Interviewers were experienced women trained specifically for this project. Interviewer performance and data quality were monitored routinely. Interviews were conducted from November 1996 through May 1997. Subjects who completed interviews received financial com- pensation. Funding was available to interview 558 subjects.

To determine whether respondents were representative of women in the national registry, a random sample of 200 nonresponders was selected. Nonresponders were assigned computer-generated random identification numbers ordered lowest to highest, and the first 200 were selected. Demographic information from the Department of Veterans Affairs decentralized electronic databases (Austin, TX) was compared with that of participants. Fifty of 200 nonresponders were interviewed by telephone to determine their reasons for not participating and to get self-appraisals of their health.

An extensive structured interview was developed to determine sociodemographic, environmental, and consequential correlates of victimization while in the military. The demographic survey inquired about background, violence history, and current medical and occupational status. The Women's Military Environment Survey was developed and piloted. It was guided by the National Academy of Sciences delineation of the four-stage process of quantitative risk assessment (hazard identification, exposure assessment, stages of doseresponse models, and risk characterization). ${ }^{16}$ Variables of women's military experience examined included occurrence of violence; work, living, and leisure environments; officer conduct toward women; work performance; and health-care access.

Respondents rated how often a series of statements was generally true of their military experiences, on a Likert-type scale, where $1=$ "never" and $5=$ "almost always." For some items, respondents were asked to indicate levels of distress they felt during particular experiences. Queries about distress were made only if respondents indicated military experiences that occurred "sometimes" or more often and levels were scaled from 1 = "very low" to 5 = "very high." Work and living quarters often are located on military bases, so we recorded victimization events and environmental factors on and off duty as work-related.

The Short Form-36 General Health Survey is a general health status measure of health-related quality of life, including positive and negative aspects of function and well-being. ${ }^{17}$ Its 36 questions are allocated to eight function domains or scales that can be summarized further by physical and mental component scores. The domains include physical function, physical role, bodily pain, general health perceptions, vitality, social function, mental health, and emotional role. The physical and mental components accounted for $82 \%$ of the reliable variance in Short Form-36 scales in the general United States population and $82 \%$ in the medical outcome studies. ${ }^{17}$ This instrument has been used in a variety of settings and has excellent reliability and 
validity, ${ }^{17}$ demonstrating sensitivity to health differences in the general population and patients with chronic diseases, and is predictive of health outcomes over time. ${ }^{18}$

Rape was defined as any act without an individual's consent that involved the use or threat of force and included attempted or completed sexual penetration of the victim's vagina, mouth, or rectum. Physical assault was defined as any act during which women believed they were in physical danger, such as being pushed, shoved, grabbed, slapped, kicked, beaten, choked, threatened, or attacked with a weapon or other object (independent of rape or domestic violence events). Dual victimization was defined as both rape and physical assault during military service. Nonvictimized refers to no rape or physical assault during military service. Domestic violence was defined as physical assault initiated by a spouse or partner. Premilitary rape and domestic violence were defined as above, but before enlistment. Childhood physical or sexual abuse were queried without detailed definitions provided.

All statistical analyses were done with STATA (STATA Software Corporation, College Station, TX) to account for complex sample survey design. Comparisons used linear models, equivalents of analysis of variance for unequal cell sizes, and adjusted means. The two-tailed $\alpha$ was set at .05.

\section{Results}

Six hundred forty women consented to participate. A precise response rate was difficult to obtain because of the many individuals never contacted. Conservative and projected response rates were estimated. Twentytwo percent (474 of 2172) of registry contact information was found to be invalid at time of the survey, most of which were incorrect addresses $(n=449)$. Additional inaccurate registry data was discovered during attempted phone calls to nonresponders. Twenty-six percent (48 of 183) had no current telephone numbers because of disconnection, incorrect number, or they had moved. Applied to the total nonresponder pool, 278 potential participants likely did not receive the initial mailing. An additional 56\% of nonresponders (23 of 50) who were contacted and interviewed by telephone never received the mailed study information. That provided a projected estimate of $870(278+592)$ nonresponders who did not receive the mailed study information. The conservative response rate was estimated to be $45 \%$ ( 640 of [ $2172-474-278=1420])$, but that likely underestimates the true response rate indicated by further attempts to contact nonresponders. Therefore, a projected response rate of $77 \%$ (640 of [2172 $474-278-592=828]$ ) might provide an upper bound for the actual response rate and a more accurate estimate than the conservative response rate calculation. Because of funding limitations, only the first 558 of 640 consenting women were interviewed. Complete interview data were available for 537 subjects.

Participants differed from nonparticipants $(n=200)$ in age (study participants were slightly older, 40.3 versus 37.7 years; $P<.003$ ), earlier military entry (18.0 versus 15.0 years; $P<.001)$, and time since discharge (12.0 versus 10.0 years; $P<.001$ ). Participants were not significantly different than nonresponders in branch of service, marital status, or service-connected disability for medical or psychiatric disorders.

Compared with nonresponders contacted by telephone $(n=50)$, participants were less likely to report poor or fair health $(28 \%$ versus $54 \% ; P<.05)$. No significant differences between participants and nonresponders were found in outpatient physician use in the past year. Most of those nonresponders $(82 \%, n=19)$ stated they would have participated in this research if study information summarized by the interviewer had been sent. Those who did receive the mailed information gave several reasons for not participating, which included being too busy $(50 \%)$; belief that the topic (sexual victimization) did not relate to their military experiences $(50 \%)$, or that the topic was too close to their military experiences (32\%); and fear that the interview would bring back bad memories $(29 \%)$.

Almost half the participants $(48 \%)$ reported some type of physical or sexual victimization during their military service. Physical assault was reported by 35\%, and most (58\%) had been assaulted at least twice. Rape was reported by $30 \%$, in $11 \%$ it was attempted and in $19 \%$ completed. Five percent of those raped reported that they had been gang raped (more than one perpetrator). Over half of the women who acknowledged rape $(54 \%)$ had been raped at least twice. Thirty-seven percent of repeated rapes were completed rapes. Sixteen percent of women veterans were physically assaulted and raped.

Twelve percent of participants were raped solely during military service, compared with one fourth who were sexually abused only during childhood, and 1\% who were raped only after military service. Fourteen percent of participants were raped before and during military service, and $4 \%$ were raped during and after military service.

Table 1 presents demographic characteristics, current health status, and victimization history of participants by type of violence experienced during military service. Women who were raped or dually victimized were more likely to report chronic health problems and use prescription medications for mental health problems. Victimized women were more likely to report violence 
Table 1. Sample Characteristics by Type of In-Military Violence Experienced

\begin{tabular}{|c|c|c|c|c|c|}
\hline & $\begin{array}{l}\text { No violence } \\
(n=279)\end{array}$ & $\begin{array}{l}\text { Physical assault } \\
\qquad(n=99)\end{array}$ & $\begin{array}{c}\text { Rape } \\
(n=70)\end{array}$ & $\begin{array}{l}\text { Rape and physical } \\
\text { assault }(n=89)\end{array}$ & $\begin{array}{c}\text { Total } \\
(n=537)\end{array}$ \\
\hline Current age (y) & $40.7 \pm .66$ & $38.4 \pm 1.16$ & $39.9 \pm 1.18$ & $38.8 \pm 1.06$ & $39.9 \pm .40$ \\
\hline Years since entry to military service & $17.5 \pm .58$ & $16.5 \pm .82$ & $18.4 \pm 1.08$ & $17.4 \pm 1.06$ & $17.4 \pm .32$ \\
\hline Years since discharge from active duty & $10.8 \pm .59$ & $10.3 \pm .96$ & $11.6 \pm 1.13$ & $12.1 \pm 1.17$ & $11.0 \pm .29$ \\
\hline \multicolumn{6}{|l|}{ Military rank } \\
\hline Officer & $36(17.6)$ & $11(10.3)$ & $5(9.2)$ & $4(3.9)^{*}$ & $56(12.5)$ \\
\hline Enlisted & $240(83.4)$ & $87(89.7)$ & $64(90.8)$ & $83(96.1)^{*}$ & $474(87.5)$ \\
\hline College graduate or higher education & $98(34.7)$ & $27(28.3)$ & $12(10.9)^{* \dagger}$ & $21(19.6)^{*}$ & $158(28.5)$ \\
\hline \multicolumn{6}{|l|}{ Race } \\
\hline White & $203(71.4)$ & $74(63.5)$ & $55(70.4)$ & $62(64.8)$ & $394(68.7)$ \\
\hline Nonwhite & $76(28.6)$ & $25(36.5)$ & $15(29.6)$ & $27(35.2)$ & $143(31.3)$ \\
\hline Annual income $>\$ 25,000$ & $164(60.0)$ & $57(62.2)$ & $37(45.0)^{* \dagger}$ & $39(41.0)^{* \dagger}$ & $297(55.6)$ \\
\hline \multicolumn{6}{|l|}{ Marital status } \\
\hline Never married & $83(27.9)$ & $25(27.4)$ & $25(47.6)^{\dagger}$ & $24(33.6)$ & $157(30.7)$ \\
\hline Married & $105(39.6)$ & $28(22.5)$ & $18(20.0)^{\dagger}$ & $31(25.0)$ & $182(31.9)$ \\
\hline Separated or divorced & $91(32.5)$ & $46(50.1)$ & $27(32.4)^{\dagger}$ & $34(41.4)$ & $198(37.3)$ \\
\hline \multicolumn{6}{|l|}{ Premilitary violence } \\
\hline Physical abuse & $77(28.7)$ & $44(39.5)$ & $29(37.7)$ & $47(47.5)^{*}$ & $197(34.9)$ \\
\hline Sexual abuse & 79 (26.3) & $38(39.0)$ & $34(44.2)^{*}$ & $46(49.3)^{*}$ & $197(34.5)$ \\
\hline Rape & $59(19.5)$ & $28(26.9)$ & $21(25.2)$ & $42(46.5)^{* \dagger \ddagger}$ & $150(26.2)$ \\
\hline Domestic violence & $43(14.7)$ & $30(30.0)^{*}$ & $12(16.2)$ & $26(24.1)$ & $111(19.4)$ \\
\hline $\begin{array}{l}\text { Joined military to escape abusive or } \\
\text { distressing home }\end{array}$ & $75(27.4)$ & $37(34.9)$ & $27(35.9)$ & $36(36.1)$ & $175(31.1)$ \\
\hline \multicolumn{6}{|l|}{ Postmilitary violence } \\
\hline Rape & $13(3.7)$ & $7(5.2)^{*}$ & $5(6.4)$ & $18(21.0)^{* \dagger \neq}$ & $43(7.3)$ \\
\hline Physical abuse & $44(13.9)$ & $27(29.4)^{*}$ & $9(10.0)^{\dagger}$ & $34(42.9)^{* *}$ & $114(21.5)$ \\
\hline Domestic violence & $31(70.5)$ & $17(62.9)$ & $7(77.8)$ & $26(76.5)$ & $81(71.1)$ \\
\hline \multicolumn{6}{|l|}{ Service-connected disability } \\
\hline Medical & $134(51.2)$ & 49 (55.6) & $33(41.8)$ & $35(41.8)$ & $251(50.1)$ \\
\hline Psychiatric, including PTSD & $17(3.6)$ & $9(7.8)$ & $5(5.1)$ & $14(10.8)$ & $45(5.8)$ \\
\hline Both medical and psychiatric & $25(8.5)$ & $9(6.3)$ & $7(12.0)$ & $17(17.6)$ & $58(10.0)$ \\
\hline \multicolumn{6}{|l|}{ Current health status } \\
\hline Current chronic medical problems & $165(63.0)$ & $61(63.3)$ & $48(72.2)$ & $74(84.6)^{* \dagger}$ & $348(67.8)$ \\
\hline $\begin{array}{l}\text { Current prescription medication use } \\
\text { for emotional or psychiatric } \\
\text { problems }\end{array}$ & $44(15.2)$ & $25(22.3)$ & $26(36.7)^{*}$ & $33(28.5)^{*}$ & $128(21.0)$ \\
\hline
\end{tabular}

PTSD = posttraumatic stress disorder.

Data are presented as mean \pm standard error of the mean or as $n(\%)$. Mean, standard error, and \% estimates account for the stratified sampling design. The $n^{\prime}$ s are actual sample counts.

${ }^{*} P<.05$ versus no violence category.

${ }^{\dagger} P<.05$ versus physical assault category.

$\ddagger P<.05$ versus rape category.

before and after military service, with dually victimized women more likely to indicate a pattern of violence. Women who were raped or dually victimized were less likely than nonvictimized peers to have completed college or earn more than $\$ 25,000$ annually.

There were no differences in insurance coverage or use of Veterans Affairs health services between participants by type of violence during military service. Half the participants were privately insured and the rest used Medicare (12\%), Medicaid $(7 \%)$, or other coverage, including veterans benefits (31\%). Only $42 \%$ received all of their health care through Veterans Affairs; 37\% received some, and $21 \%$ received no care through it.

Table 2 presents data on health-related quality of life, stratified by type of violence. Dually victimized women had the greatest health impairment. Women raped during military service had significantly poorer health than nonvictimized women. Women who were physically assaulted showed quality of life similar to nonvictimized women, with the exception of physical role domain, in which their impairment was similar to that of dually victimized women. In that domain, physically and dually victimized women's scores were below the 25th percentile compared with the general population, indicating problems with work or other daily activities because of physical health. ${ }^{19}$

Table 3 presents adjusted means of health-related quality of life by type of violence. It was not possible to 
Table 2. Unadjusted Mean Short Form-36 Scores by Reported Military Violence Type $(N=537)$

\begin{tabular}{lcccc}
\hline Short Form-36 subscale & $\begin{array}{c}\text { No violence } \\
(n=279)\end{array}$ & $\begin{array}{c}\text { Physical assault } \\
(n=99)\end{array}$ & $\begin{array}{c}\text { Rape } \\
(n=70)\end{array}$ & $\begin{array}{c}\text { Physical assault } \\
\text { and rape }(n=89)\end{array}$ \\
\hline Physical functioning & $74.1(2.2)$ & $67.0(4.5)$ & $72.4(3.7)$ & $69.7(3.9)$ \\
Role-physical & $57.6(3.5)$ & $42.6(5.5)$ & $47.0(6.4)$ & $42.7(6.4)^{*}$ \\
Bodily pain & $57.6(2.3)$ & $60.4(4.6)$ & $56.8(4.6)$ & $51.7(4.7)$ \\
General health & $64.8(2.1)$ & $59.1(4.5)$ & $55.2(3.5)^{*}$ & $52.8(4.0)^{*}$ \\
Vitality & $51.5(1.9)$ & $47.3(3.6)$ & $44.1(3.0)^{*}$ & $62.9(3.3)^{*}$ \\
Social functioning & $77.6(2.2)$ & $70.1(4.6)$ & $66.8(4.5)$ & $64.7(4.7)^{*}$ \\
Role-emotional & $80.2(2.7)$ & $70.0(5.8)$ & $63.8(6.9)^{*}$ & $62.5(3.6)^{*}$ \\
Mental health & $73.2(1.6)$ & $66.9(4.2)$ & & $60.1(3.3)^{*}$ \\
\hline
\end{tabular}

Unadjusted means used to test for effect of type of in-military violence.

Data are given as mean (standard error).

${ }^{*} P<.05$ versus no violence category.

$\dagger P<.05$ versus physical assault category.

conclude that the differences in current health status necessarily were associated with violence during military service. Therefore, we calculated the effect of victimization by group controlling for several background characteristics, including race, marital status, education, premilitary and postmilitary victimization, and service-connected disability status. Even after controlling for those factors, violence during military service was a significant correlate of impaired quality of life. Women who were physically assaulted and raped had the most impaired health status across all domains, which shows that dually victimized women have problems with work, social, and other daily activities caused by physical and emotional health problems. Those women felt body pain, tiredness, nervousness, and depression much of the time and evaluated their health as poor and likely to get worse. In the dually victimized group, adjusted health status measures consistently were at or below the 25th percentile compared with national norms. Adjusted scores of dually victimized women were lower than average when compared with populations of men and women who recently survived acute myocardial infarctions or diabetes mellitus type $\mathrm{II}^{17}$ and were similar to those of patients with advanced Parkinson disease. ${ }^{20}$

\section{Discussion}

This study provides compelling evidence that sequelae of violence against women should be considered an important public health concern. More than a decade after their military service, women with histories of physical and sexual violence during military service were more likely to report poorer health status than those without such histories. Even after controlling for demographic and lifetime trauma factors, that finding persisted. Subjects who were raped and physically assaulted during military service reported the poorest health statuses. Cumulative physical and emotional sequelae of rape and physical assault were similar to or worse than those associated with major chronic illnesses.

Our findings suggest that there are unique healthrelated effects of physical versus sexual assault that

Table 3. Adjusted Mean Short Form-36 Scores by Reported Military Violence Type $(N=537)$

\begin{tabular}{|c|c|c|c|c|}
\hline Short Form-36 subscale & $\begin{array}{l}\text { No violence } \\
\quad(n=279)\end{array}$ & $\begin{array}{l}\text { Physical assault } \\
\qquad(n=99)\end{array}$ & $\begin{array}{c}\text { Rape } \\
(n=70)\end{array}$ & $\begin{array}{c}\text { Physical assault } \\
\text { and rape }(n=89)\end{array}$ \\
\hline Physical functioning & $73.0(1.1)$ & $72.2(1.9)$ & $71.1(2.0)$ & $68.3(1.9)^{*}$ \\
\hline Role-physical & $55.8(1.2)$ & $50.1(1.9)^{*}$ & $48.7(2.3)^{*}$ & $39.4(2.6)^{* \dagger \#}$ \\
\hline Bodily pain & $58.4(0.3)$ & $57.4(0.6)$ & $54.7(0.5)^{* \dagger}$ & $53.4(0.4)^{* \dagger \neq}$ \\
\hline General health & $64.4(0.7)$ & $60.3(1.2)^{*}$ & $57.5(1.4)^{*}$ & $51.5(1.5)^{* \dagger \neq}$ \\
\hline Vitality & $51.3(0.5)$ & $47.4(0.9)^{*}$ & $47.6(1.2)^{*}$ & $41.6(1.4)^{* \dagger \sharp}$ \\
\hline Social functioning & $77.0(0.8)$ & $71.5(1.5)^{*}$ & $71.9(1.7)^{*}$ & $62.4(2.2)^{* \dagger \neq}$ \\
\hline Role-emotional & $80.1(1.0)$ & $69.1(2.2)^{*}$ & $68.3(2.2)^{*}$ & $51.4(2.8)^{* \dagger+\frac{1}{4}}$ \\
\hline Mental health & $72.9(0.5)$ & $67.2(1.0)^{*}$ & $66.4(1.3)^{*}$ & $58.6(1.5)^{* \dagger \ddagger}$ \\
\hline
\end{tabular}

\footnotetext{
Adjusted means used to test for effect of type of in-military violence after controlling for age, race, service-connected disability, premilitary and postmilitary violence.

Data are given as mean (standard error).

${ }^{*} P<.05$ versus no violence category.

${ }^{\dagger} P<.05$ versus physical assault category.

$\ddagger P<.05$ versus rape category.
} 
might affect how women present for health care. Women who were physically assaulted during military service reported problems with physical health, whereas women who were raped evaluated their health as poor with compromised function across all mental health domains. Women raped during military service also had poorer economic and educational achievements.

Our cohort entered the military an average of 18 years before the current study, with an average length of time since discharge of 11.5 years. The high degree of current health status impairment, which is so long from the period of victimization, suggests that the negative health consequences of rape and physical assault are severe and chronic. Perhaps there are unique characteristics of military violence that contribute to that outcome. Repeated exposure to interpersonal violence during military service or factors relating to access to medical services not addressed in this research might contribute to the effect of such trauma during military service on subsequent health. Even nonvictimized women had compromised health-related quality of life, which likely results from the clinical nature of the registry population, but might indicate occupational exposures in the military workplace that were not assessed. Further investigation of those findings is warranted. This research has implications for improved violence prevention and intervention training in orientations for military women.

Our findings that victimized women's health-related quality of life is adversely affected supports the necessity of routine assessment of histories of violence. Few civilian victims of sexual assault seek formal mental health services or victim assistance immediately after an assault, but research indicates that $98 \%$ make outpatient physician visits in the first year after victimization. ${ }^{14}$ Unfortunately, primary care providers rarely screen women for interpersonal violence, and women infrequently volunteer that information without direct invitation. ${ }^{21}$ We believe that women's experiences of workplace violence are addressed even less frequently. The American Medical Association Council on Scientific Affairs expressed concern that clinicians are rarely trained to deal with violence toward women. ${ }^{22}$

Obstetrician-gynecologists are on the front line of identification and intervention for many victims of rape and assault. Almost one third (29\%) of all ambulatory care visits for women aged 15-44 years are to obstetrician-gynecologists, ${ }^{22}$ and approximately half of women consider obstetrician-gynecologists to be their primary care providers. ${ }^{23}$ That relationship provides a unique opportunity to identify and, in collaboration with mental health professionals, treat short-term and long-term medical consequences of violence toward women.
Women who participated in this study reported that they had the means and propensity to seek care from the private sector. Dually victimized women were most severely compromised across physical and emotional domains and will likely present with health complaints, psychological distress, lower economic and educational achievements, and histories of repeated violence. If clinicians overlook trauma as a potential etiologic factor for women with those types of symptoms, they might make erroneous diagnoses and initiate treatment interventions that do not address the problem.

Our findings that women with no trauma or a single type of trauma during military service had significantly better health status support the importance of early intervention. Clinical interventions after a single victimization incident might maintain women's health or interrupt a cycle of violence by moderating emotional and behavioral consequences. Despite increasing emphasis on women's access to preventive health services, screening, prevention, and treatment programs for violence toward women have remained underdeveloped, which is particularly striking when compared with other public health problems with lower lifetime prevalence rates, such as cervical cancer $(0.79 \%)$ or breast cancer $(13 \%),{ }^{24}$ and burden of illness. Globally, the health burden from violence toward women $(9.5$ million disability-adjusted life years) is comparable to other major public health problems, such as HIV (10.6 million), tuberculosis (10.9 million), sepsis during childbirth (10 million), and cardiovascular disease (10.5 million). ${ }^{10}$

Our research was not intended or designed to investigate prevalence estimates of violence against women veterans, which are already available. However, we found rates of violence similar to those of military and civilian populations. Forty-seven percent of our participants had been sexually abused during childhood, raped, or both before military service. That is consistent with findings by Koss, ${ }^{25}$ who estimated that $38-67 \%$ of adult women recall sexual assault during childhood or adolescence. A lower rate of childhood sexual abuse $(27 \%)$ was found in a national survey of adult civilian women. ${ }^{26}$ Compared with recent studies of active-duty military women, the rate of childhood sexual victimization of our subjects (35\%) was within the reported range (25-50\%). ${ }^{27,28}$ We found higher rates of childhood physical abuse $(35 \%)$ compared with that reported in the general population $(25 \%)$ by child protective services. ${ }^{29}$ However, compared with female army soldiers, our rate of childhood physical abuse solely was similar (11\% versus $15 \%) .{ }^{27}$ Our findings of attempted or complete rapes during military service (30\%) were similar to those of other studies of female veterans that found 
rates of attempted or completed rapes ranging from $8-29 \% .6,7,27,30$ Caution is necessary when comparing rates of violence because differences in research definitions, methods, and samples affect results.

This study had several potential limitations. Response rates were difficult to estimate. Other investigators have found that female veterans are often difficult to locate. ${ }^{30}$ One important survey of women veterans and violence yielded response rates of only $29 \%{ }^{30}$ The conservatively estimated response rate also could be considered overly modest. A pattern of low response rates was found in other sexual violence survey research. In a recent review, only six of 20 sexual harassment studies of civilians had return rates above $50 \%{ }^{31}$ Research that assessed rape in women veterans used convenience samples ${ }^{6,7,32}$ or a self-selected subset of women participating in a multi-phase study. ${ }^{30,32}$

Results might not be generalizable to active-duty military women because of cross-sectional design and characteristics of the sample. Most of our participants were white, thus our results might not be generalizable to racial or ethnic minorities. Our participants also might differ from the general female veteran population because they were selected from a registry primarily composed of women who have used the Veterans Affairs system or who sought disability. Not all women selected for inclusion chose to participate. Concerns about the representativeness of the sample to the general female veteran population are lessened by the similarity of the rates of victimization in this study with those reported in other research that focused on recent women veterans. ${ }^{6,7,28,30}$

Most information collected in this study was selfreported and required responders to recall information on experiences that happened many years earlier. Memory failure, telescoping of events into or out of the reference period (specific details forgotten, partial memory failure in which events are misplaced in time), and decreased willingness to report victimization because of knowledge that a more detailed interview would follow (time-in-sample bias) could have affected findings. ${ }^{33}$

Victimized women might have been more likely than their peers to participate because of the relevance of their experiences. Conversely, they might be less likely to do so because they do not wish to think about traumatic experiences. The degree of either form of sample bias is not known; however, interviews with nonresponders indicated that both types of selfselection occurred at roughly equal rates. The inclusion of victimization events on and off duty as work-related might also be considered a limitation.

\section{References}

1. American Medical Association. Strategies for treatment and prevention of sexual assault. Chicago: American Medical Association, 1995.

2. Tjaden P, Thoennes N. Prevalence, incidence, and consequences of violence against women: Findings from the national violence against women survey. Atlanta: National Institute of Justice \& Centers for Disease Control and Prevention, 1998.

3. Ramin SM, Satin AJ, Stone IC, Wendel GD. Sexual assault in postmenopausal women. Obstet Gynecol 1992;80:860-4.

4. Peek-Asa C, Howard J, Vargas L, Kraus JF. Incidence of non-fatal workplace assault injuries determined from employers reports in California. J Occup Environ Med 1997;39:44-50.

5. Bureau of Labor Statistics. News: Characteristics of work injuries and illnesses resulting in absences from work. Washington, DC: US Department of Labor, 1996.

6. Coyle BS, Wolan DL, Van Horn AS. The prevalence of physical and sexual abuse in women veterans seeking care at a Veterans Affairs Medical Center. Milit Med 1996;161:588-93.

7. Murdoch M, Nichol KL. Women veterans' experiences with domestic violence and with sexual harassment while in the military. Arch Fam Med 1995;4:411-8.

8. Clancy CM, Massion CT. American women's health care. A patchwork quilt with gaps. JAMA 1992;268:1918-20.

9. Walker EA, Unutzer J, Rutter C, Gelfand A, Saunders K, VonKorff $\mathrm{M}$, et al. Costs of health care use by women HMO members with a history of childhood abuse and neglect. Arch Gen Psychiatry 1999;56:609-13.

10. World Bank World Development Report 1993. Investing in health. New York: Oxford University Press, 1993.

11. Geist RF. Sexually related trauma. Emerg Med Clin North Am 1988;6:439-66.

12. Jenny C, Hooton TM, Bowers BA, Compass MK, Krieger JN, Hillier $\mathrm{SL}$, et al. Sexually transmitted diseases in victims of rape. N Engl J Med 1990;322:713-6.

13. Harlow CW. Injuries from crime. Washington, DC: Department of Justice, Bureau of Justice Statistics, 1989.

14. Koss MP, Koss PG, Woodruff WJ. Deleterious effects of criminal victimization on women's health and medical utilization. Arch Intern Med 1991;151:342-7.

15. Drossman DA, Lesserman J, Nachman G, Liz M, Gluck H, Toomey TC, et al. Sexual and physical abuse in women with functional or organic gastrointestinal disorders. Ann Intern Med 1990;113:82833.

16. Wartenberg D, Simon R. Comment: Integrating epidemiologic data into risk assessment. Am J Public Health 1995;85:491-3.

17. Ware JE, Kosinski M, Keller SD. SF-36 Physical and mental health summary scales: A user's manual. Boston: The Health Institute, New England Medical Center, 1994.

18. Huppert FA, Whittington JE. Symptoms of psychological distress predict 7-year mortality. Psychol Med 1995;25:1073-86.

19. Schappert SM. National ambulatory medical care survey: 1991 survey. Vital Health Stat 1994;116:1-110.

20. Rubenstein LM, Voelker MD, Chrischilles EA, Glenn DC, Wallace RB, Rodnitzky RL. The usefulness of the functional status questionnaire (FSQ) and the medical outcomes study short form (SF-36) in Parkinson's disease research. Quality Life 1998;7:279-90.

21. Liese BS, Larson MW, Johnson CA, Hourigan RJ. An experimental study of two methods for teaching sexual history taking skills. Fam Med 1989;21:21-4.

22. American Medical Association. Violence against women. Relevance for medical practitioners. Council on Scientific Affairs. JAMA 1992;267:3184-9.

23. Higgins RV, Hall JB, Laurent S. Primary care by obstetricians and 
gynecologists: Attitudes of the members of The South Atlantic Association of Obstetricians and Gynecologists. Am J Obstet Gynecol 1997;177:311-8.

24. Feuer EJ, Wun LM, Boring CC, Flanders WD, Timmel MJ, Tong T. The lifetime risk of developing breast cancer. J Natl Cancer Inst 1993;85:892-7.

25. Koss MP. Women's mental health research agenda: Violence against women. Women's Mental Health Occasional Paper Series. Washington, DC: National Institute of Mental Health, 1990.

26. Finkelhor D, Hotaling G, Lewis IA, Smith C. Sexual abuse in a national survey of adult men and women: Prevalence, characteristics, and risk factors. Child Abuse Negl 1990;14:19-28.

27. Rosen LN, Martin L. The measurement of childhood trauma among male and female soldiers in the U.S. army. Milit Med 1996;161:342-5.

28. Martin L, Rosen LN, Durand DB, Stretch RH, Knudson KH. Prevalence and timing of sexual assaults in a sample of male and female U.S. Army soldiers. Milit Med 1998;163:213-6.

29. US Department of Health and Human Services. The third national incidence study of child abuse and neglect. Washington, DC: US Government Printing Office, 1996.

30. Wolfe J, Brown PJ, Bucsela ML. Symptom responses of female Vietnam veterans to Operation Desert Storm. Am J Psychiatry 1992;149:676-9.

31. Rubin LJ, Borgers SB. Sexual harassment in universities during the 1980's. Sex Roles 1990;23:397-411.
32. Engel CC Jr, Engel AL, Campbell SJ, McFall ME, Russo J, Katon W. Posttraumatic stress disorder symptoms and precombat sexual and physical abuse in Desert Storm veterans. J Nerv Ment Dis 1993;181:683-8.

33. Klein PJ, Gerberich SG, Gibson RW, Maldonado G, Kruttschnitt C, Larntz K, et al. Risk factors for work-related violent victimization. Epidemiology 1997;8:408-13.

Address reprint requests to:

Anne G. Sadler, RN, PhD

Veterans Affairs Medical Center

$116 B$

Iowa City, IA 52246

E-mail: asadler@icva.gov

Received September 2, 1999

Received in revised form March 16, 2000.

Accepted April 13, 2000.

Published by Elsevier Science Inc. 